\title{
EMBEDDED MICROSTRIP LINE TO STRIPLINE VERTICAL TRANSITION USING LTCC TECHNIQUE
}

\author{
Beeresha R S ${ }^{1}$, A M Khan ${ }^{2}$, Manjunath Reddy $\mathbf{H ~ V}^{3}$, Ravi $\mathrm{S}^{4}$ \\ ${ }^{1}$ Research Scholar, Department of Electronics, Mangalore University, Karnataka, India \\ ${ }^{2}$ Prof and Chairman, Department of Electronics, Mangalore University, Karnataka, India \\ ${ }^{3}$ General Manager, RF\& Microwave Design,ICON Design Automation Ltd, Karnataka India \\ ${ }^{4}$ Research Scholar, Department of Electronics, Mangalore University, Karnataka, India
}

\begin{abstract}
The low-temperature co-fired ceramic (LTCC) design technology is a present trend in high frequency application designs. The behavior of passive RF/microwave frequency components needs to be investigated to understand transition effect of a signal in a multilayer circuit. The aim of this paper is to design low-loss unlike-media transition model of microstrip to stripline in multilayer circuits. The transition models were designed using different conducting materials like silver, gold and copper, also for simulation studies an ideal reference model known as 'perfect conductor' (PEC) is used. The selected transition bandwidth is in the range $1 \mathrm{GHz}$ to $30 \mathrm{GHz}$. The analysis of the transition effect is done with the help of scattering parameters. The perfect conductor is a reference conductor for studying transition losses. The electromagnetic (EM) simulated results of the perfect conductor obtained using NI/AWR EDA environment is compared with silver and copper conductor material models. The observed results of silver and copper conductor models lies very close to the results obtained using PEC (perfect) conductor model. From the studies done we conclude that the design \& simulation of ultra-wide band transition microstrip line to stripline( $1 \mathrm{GHz}$ to 30GHz) is possible with good in insertion loss \& return loss.
\end{abstract}

Keywords-NI/AWR, Copper conducting material, EM Simulation, LTCC, Microstrip line, PEC (perfect) conductor, Silver conducting material, Stripline, System on Chip, Transition.

\section{INTRODUCTION}

The embedded passive RF/Microwave components find wide applications in the areas such as industries, medicine, military and space. These automotive applications offer certain challenges in terms of package density and design technology with an increased efficiency.

These challenges are tried to overcome in unique technique such as System on Chip (SoC). This technique is not only good for package density but also is reliable in electrical and thermal performances.

The research trend in SoC is focused on different packaging technologies like Low-Temperature Co-fired Ceramic (LTCC) and Multi-Chip Module (MCM). The traditional multilayer Hybrid Microwave Integrated Circuit (HMIC) technique has few limitations like it has more packaging size, difficult to edit $\mathrm{PCB}$, not suitable for higher temperature applications and is not economical. The LTCC technique is used to overcome these flaws of HMIC [1].

The LTCC is most promising technique based on system on chip (SOC) approach [2]. The potential of this approach makes it more suitable to design and develop compact RF/Microwave module [3], [4]. This package is a multilevel structure that allows conducting traces to be embedded within the substrate [5].
This technology also helps to build circuits over a virtually infinite number of ceramic layers [6]. The layers are designed independently and then stacked, laminated and fired at particular temperature to embed with each other. It helps to reduce the size of the design.

The efficiency of LTCC designed model is affected by various designing issues like interconnecting material, discontinuity of the transmission lines, selection of conductor and dielectric material. These parameters are also necessary to transit the signal from one transmission line to other in MIC. The transition from unlike media such as microstrip to stripline, microstrip line to coaxial line, microstrip line to coupled wave guides are complex in nature for the transition analysis [7].

This paper describes a model to design low-loss unlike media transition between microstrip lines to stripline. These transmission lines are designed in different layers and interconnect with the help of vertical via and conducting materials are assumed to be of silver, copper, gold and perfect conductor. The perfect conductor is a lossless reference conductor available for simulation studies in NI/AWR tool. The electromagnetic simulated results of copper and silver are compared with the perfect conductor. The observed results show that the copper conductor is better than silver conductor with respect to transition efficiency for ultra-wideband applications. 
The paper is organized as follows; Section II presents the design approach for microstrip line to stripline transition. In section III specific realization of the above said three different conductor models of microstrip line to stripline transition in MIC is discussed briefly. In section IV, the simulated results using silver and copper are compared and discussed along with perfect conductor. In section $\mathrm{V}$ we summarize the obtained results.

\section{DESIGN TOOL}

The transition models are simulated by microwave office tool of AWR (Applied Wave Research) corporation. The electromagnetic (EM) simulators use Maxwell equations to compute the response of a structure from its physical geometry. It can be applied to study complex 3D structures composed of linear and isotropic or anisotropic media [8]. This analysis method has great accuracy and presents attractive advantages to minimize computation time and provides better accurate results [9].

\section{PROPOSED DESIGN}

The design is focused on unlike media transition between microstrip to stripline in multilayer structure. The layers are constructed using LTCC technique. The proposed design involves four different layers, the first layer comprises of air as a dielectric media of $10 \mathrm{~mm}$ thickness and second dielectric material is alumina of $10 \mathrm{~mm}(\mathrm{Er}=9.9)$ thickness. The layers thickness and type of material is selected depending upon the operating frequency. The operating frequency window of our design is $1 \mathrm{GHz}$ to $30 \mathrm{GHZ}$.

Since the first and the second layer have different dielectric medium, it provides a suitable environment to construct microstrip line. The transmitting signal in this environment is quasi-transfer electromagnetic mode (Q-TEM).

The third and fourth layers are constructed using PCB (Printed Circuit Board) of thickness $14.8 \mathrm{~mm}(\mathrm{Er}=5.7)$ each. The third layer will act as a dielectric media between unlike transmission lines. In fourth layer, the conductor is surrounded by the vias and thus acts as a stripline. The transition mode in stripline is transfer electromagnetic mode (TEM).

The vias are designed using discontinuity technique to avoid the transition loss. The discontinued via is used to interconnect the unlike transmission lines from second layer to fourth layer. The design is made such that the impedance of the via between layer two to layer three is smaller than the impedance between layer three to four.

The signals are applied to microstrip line and treated as port 1 (input), and the output is obtained across stripline and it termed as port 2 (output). The proposed design is implemented on AWR simulation platform to study the transition efficiency by changing conductor material. The efficiency of transition obtained is measured by using scattering parameters (S-parameters).

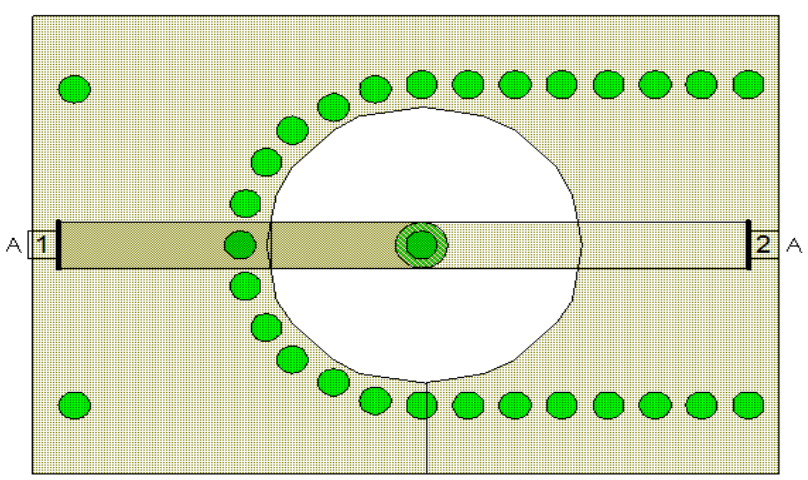

Fig-1: Layout structure of transition model

Fig. 1 shows the $2 \mathrm{D}$ view of the proposed design. The $2 \mathrm{D}$ layout structure of transition model shows only the top layer. Generally in a 2D view, it is difficult to observe transmission lines crossing layers, placing vias and interconnections in multilayer.

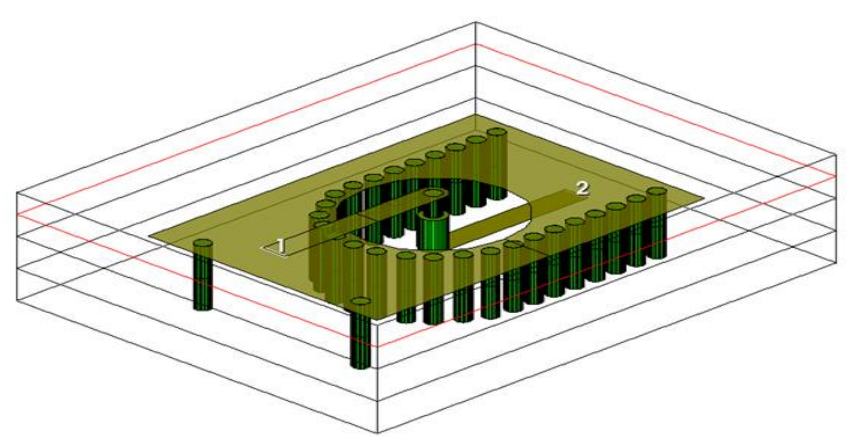

Fig-2: 3D structure of microstrip to stripline

The 2D layouts can be used to visualize the $3 \mathrm{D}$ structure of the design, using NI/AWR tool and is shown in fig. 2. This structure gives the detailed information of designed layer. We can easily edit the circuits interconnecting points. The vias are used to cover lower metal layers and connected to output port (stripline) placed in foruthlayer, the other metal layer is connected to input port (microstripline) in second layer.

The third layer acts as a dielectric medium between two layers. Microstrip line to stripline interconnection is established using vias. The selected frequency signal passes from second layer to fourth layer vertically through vias. This type of structure transition is called vertical transition.

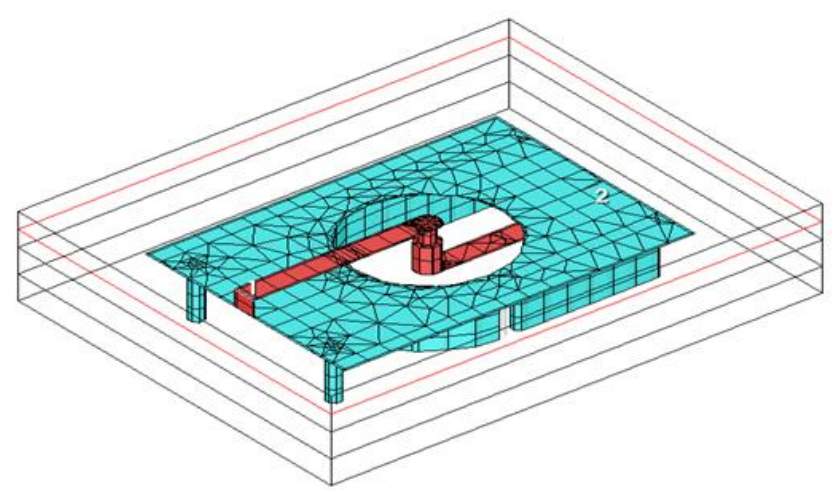

Fig-3: 3D Mesh structure 
The fig. 3 shows the 3D mess structure that helps to understand the network arrangements inside the transition model.

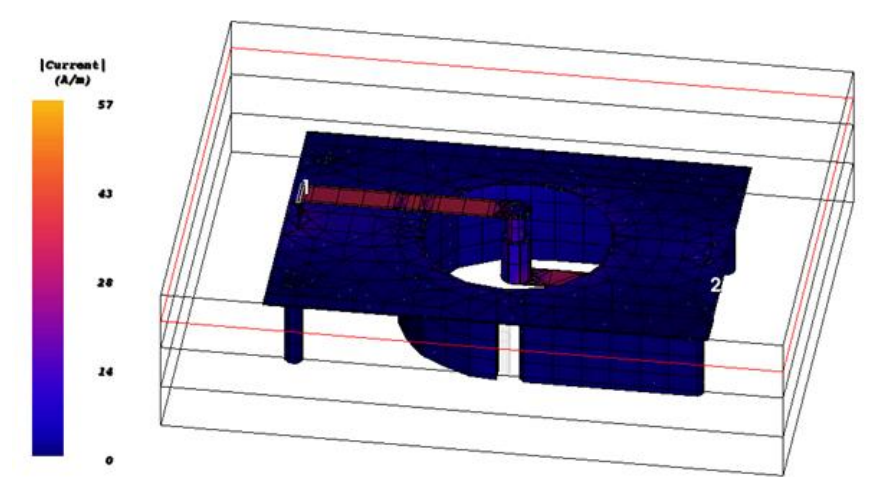

Fig-4: Flow of current on transmission line

The fig. 4 shows the flow of current per meter inside the designed model. The flow of current is highlighted using a color code where the red color implies maximum current and the blue implies minimum current.

\subsection{Conducting Materials}

The transition of the signal depends on the type of material used for designing the transmission lines. This paper discusses two different transmission-line conducting materials, vizsilver and copper, to study the signal transition in unlike media. The resultant transition efficiency is compared with the reference conducting material.

The scattering parameter technique is used to calculate insertion loss and return loss of the transmission line. The results are plot as frequency v/s loss. The experiment is done in the frequency range of $1 \mathrm{GHz}$ to $30 \mathrm{GHz}$. The following sections briefly explain the design and the obtained results using silver and copper.

\subsection{Silver Conducting Material}

The transmission lines and vias of the proposed model is designed using silver material. The silver possesses low signal loss, lesser weight, and is a good conductor which is used in RF/Microwave and other applications. The fig.5 shows response of signal transition from microstripline to stripline.

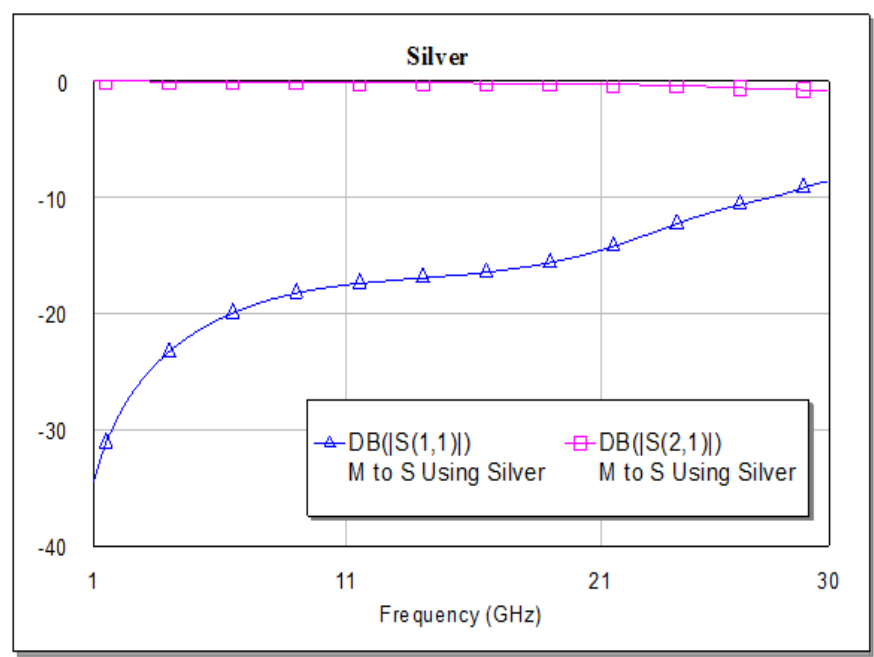

Fig-5: Insertion and return loss of silver

The observed result reflects that the insertion loss of silver is $-36 \mathrm{~dB}$ at $1 \mathrm{GHz}$ and has linear increase of the loss with respect to increasing frequency. The highest loss of $-11 \mathrm{~dB}$ is found at $30 \mathrm{GHz}$. The return loss should be less than $-0.8 \mathrm{~dB}$ for all practical purposes. The proposed design meets the standard low loss with a value approximately equal to zero at $1 \mathrm{GHz}$ and $-0.3 \mathrm{~dB}$ at $30 \mathrm{GHz}$.

\subsection{Copper Conducting Material}

Copper is a better conductor than silver because of better electrical performance and low resistance at higher frequencies, good heat dissipation, and has high tensile strength [10].

The figure 6 shows insertion and return loss of designed model using copper. The insertion loss is $-27 \mathrm{~dB}$ at $1 \mathrm{GHz}$ and $-7 \mathrm{~dB}$ at $30 \mathrm{GHz}$. The observed return is loss near to zero at $1 \mathrm{GHz}$ and $-0.2 \mathrm{~dB}$ at $30 \mathrm{GHz}$.

\subsection{Perfect Conducting Material}

The perfect conductor is the reference conductor for insertion and return loss of the transition model. The dielectric materials in the second and fourth layers are replaced by the perfect conductor for the comparative study. The dielectric material is considered as zero tangent loss with dielectric constant 5.7 in second layers and 9.9 in fourth layer. The thickness of the conductor is maintained $0.1 \mathrm{~mm}$ as considered for the other materials.

The fig. 7 shows the loss versus frequency graph of the transition model using perfect conductor material. The observed outcomes are treated as reference result. 


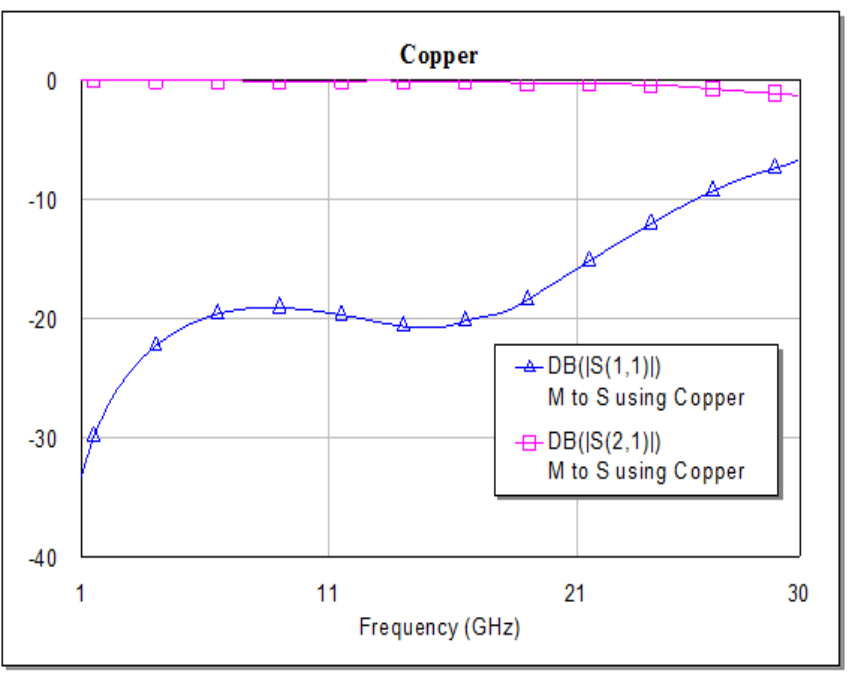

Fig-6: Insertion and return loss using copper material

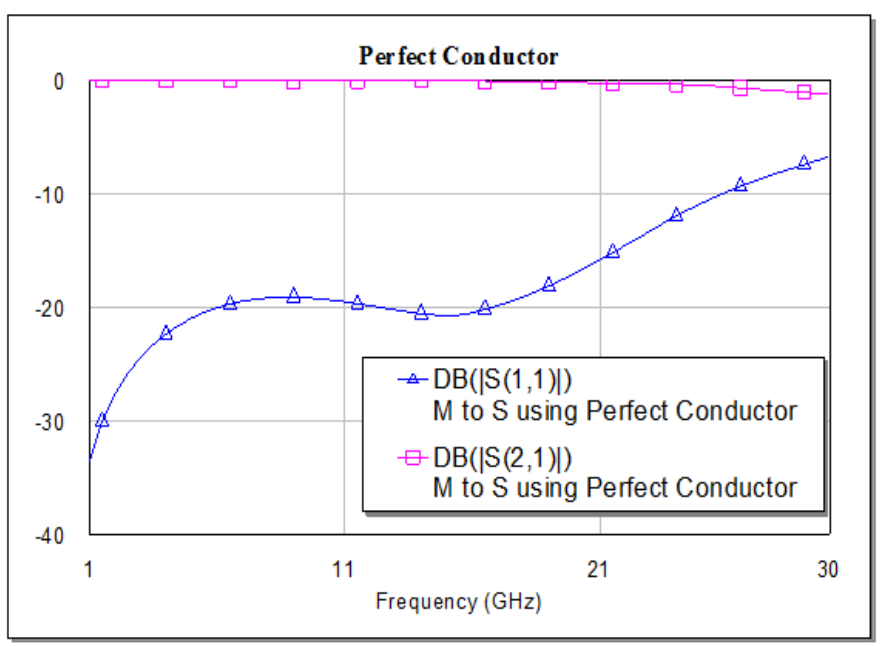

Fig-7: Insertion and return loss of the perfect conductor

\section{RESULTS AND DISCUSSION}

The four substrate layers for design transition models are of $0.1 \mathrm{~mm}$ conductor thickness. Suitable substrate materials with calculated height, width and thickness are considered. This designed model is implemented using copper and silverconductor materials along with perfect conductor of ultra-wide band range.

The selected input frequency signal is applied across port 1. The signal travels through microstrip line in Q-TEM mode then transmits using vias to other end of the stripline. The stripline changes Q-TEM mode to TEM mode. Due to this the insertion loss do not matches completely with the perfect conductor. The observed results also show that return loss is comparable with perfect conductor.

The fig.8 shows the insertion loss of silver, copper and perfect conductor material. silver and copper insertion loss is compared with perfect conductor. The response of the copper matches better with perfect conductor over the operating range. The observed EM simulated results reflect that copper than silver gives better performance if compared with the perfect conductor.

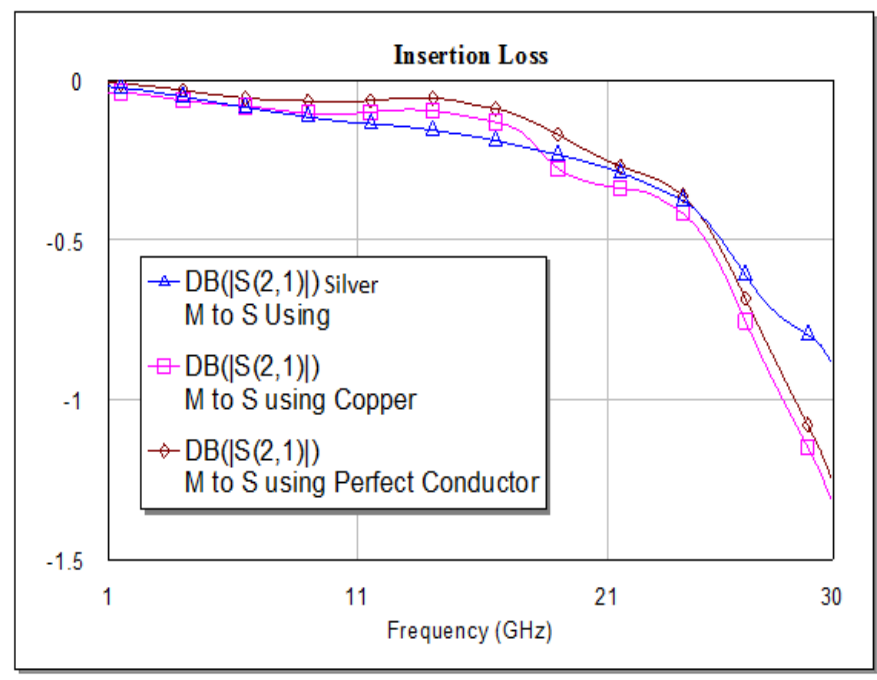

Fig-8: Insertion loss

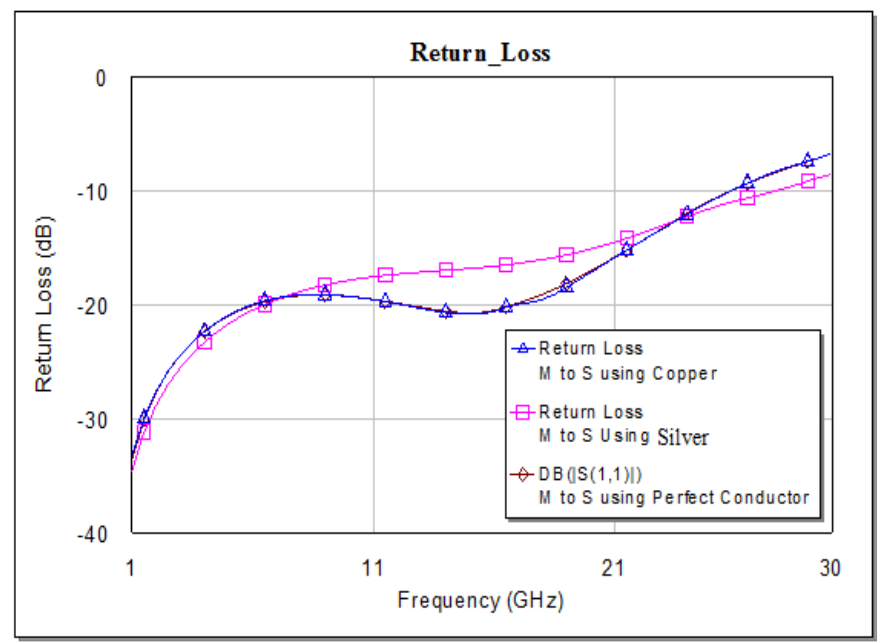

Fig-9: Return loss

The fig. 9 shows the plot of return loss obtained for the designed model using silver, copper and perfect conductor. The obtained results prove that the performance of copper conducting material is in line with perfect conductor than the silver conducting material.

The results show that the copper conducting material has performance that matches with perfect conductor, which is considered as reference model for all practical purposes, in both return loss and insertion loss. The insertion and return loss obtained using the designed model over the frequency range from $1 \mathrm{GHz}$ to $30 \mathrm{GHz}$ is tabulated as shown in Table. 1 and the corresponding comparative graph is shown in fig. 10 and fig. 11 .

Table 1: Insertion and return loss of designed models

\begin{tabular}{|l|l|l|l|l|l|l|}
\hline \multirow{2}{*}{$\begin{array}{l}\text { Freque } \\
\text { ncy in }\end{array}$} & \multicolumn{2}{l|}{$\begin{array}{l}\text { Perfect } \\
\text { Conductor }\end{array}$} & \multicolumn{2}{l|}{\begin{tabular}{l}
\multicolumn{2}{l|}{ silver } \\
Conductor
\end{tabular}} & \multicolumn{2}{l|}{$\begin{array}{l}\text { Copper } \\
\text { Conductor }\end{array}$} \\
\cline { 2 - 7 } $\mathrm{GHz}$ & Retu & Inserti & Retu & Inserti & Retu & Inserti \\
& rn & on & rn & on & rn & on \\
& Loss & loss & Loss & loss & Loss & loss \\
& $\left(\mathrm{S}_{11}\right)$ & $\left(S_{21}\right)$ & $\left(S_{11}\right)$ & $\left(S_{21}\right)$ & $\left(S_{11}\right)$ & $\left(S_{21}\right)$ \\
& in - & in $-d B$ & in - & in $-d B$ & in - & in $-d B$ \\
\hline
\end{tabular}




\begin{tabular}{|l|l|l|l|l|l|l|}
\hline & $\mathrm{dB}$ & & $d B$ & & $d B$ & \\
\hline 1 & $\begin{array}{l}33.5 \\
3\end{array}$ & 0.0055 & $\begin{array}{l}34.5 \\
9\end{array}$ & 0.0189 & 33.2 & 0.0366 \\
\hline 5 & $\begin{array}{l}20.9 \\
9\end{array}$ & 0.0386 & $\begin{array}{l}21.6 \\
7\end{array}$ & 0.0641 & $\begin{array}{l}20.9 \\
1\end{array}$ & 0.0725 \\
\hline 10 & $\begin{array}{l}19.2 \\
6\end{array}$ & 0.0723 & $\begin{array}{l}17.8 \\
4\end{array}$ & 0.1250 & $\begin{array}{l}19.2 \\
7\end{array}$ & 0.1058 \\
\hline 15 & $\begin{array}{l}20.7 \\
1\end{array}$ & 0.0606 & $\begin{array}{l}16.8 \\
1\end{array}$ & 0.1677 & $\begin{array}{l}20.8 \\
3\end{array}$ & 0.1064 \\
\hline 20 & $\begin{array}{l}17.1 \\
2\end{array}$ & 0.2657 & $\begin{array}{l}15.1 \\
2\end{array}$ & 0.2518 & $\begin{array}{l}17.1 \\
7\end{array}$ & 0.3130 \\
\hline 25 & $\begin{array}{l}10.8 \\
3\end{array}$ & 0.4760 & $\begin{array}{l}11.5 \\
2\end{array}$ & 0.4438 & 10.9 & 0.5089 \\
\hline 30 & $\begin{array}{l}6.69 \\
8\end{array}$ & 1.251 & 8.54 & 0.8887 & 6.71 & 1.326 \\
\hline
\end{tabular}

\& $-0.0189 \mathrm{~dB}$ to $-0.8888 \mathrm{~dB}$ respectively) in the operating range of $1 \mathrm{GHz}$ to $30 \mathrm{GHz}$. A novel signal transition model designed for silver and copper in this paper gives improved efficiency of the signal transition which is comparable to the lossless model, in terms of insertion and return loss over the given ultra-wide band range.

\section{ACKNOWLEDGMENTS}

The authors would like to thank Paul Shine Eugine and ICON design Automation Pvt Ltd Bangalore, for their assistance and guidance to carrying this work.

\section{REEFERENCES}

[1] Huei-Han Jhuang and Tian-Wei Huang, "Design for Electrical Performance of Wideband Multilayer LTCC," IEEE Electronics package Technology Conference, Taiwan, 2004.

\section{RETURN LOSS}

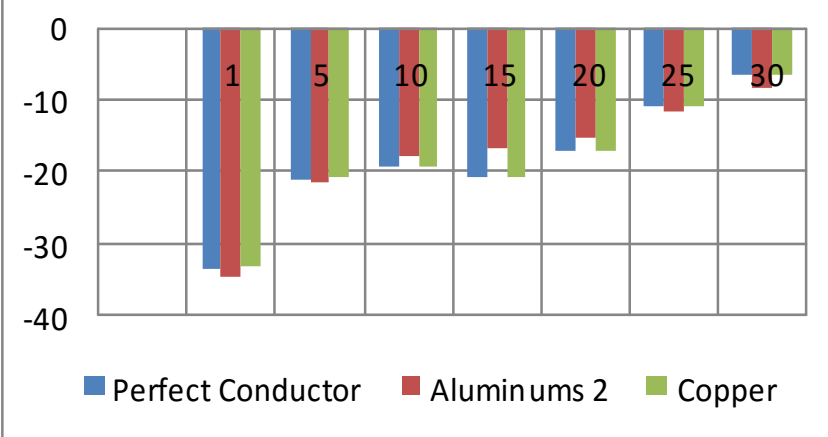

Fig-10: Return loss

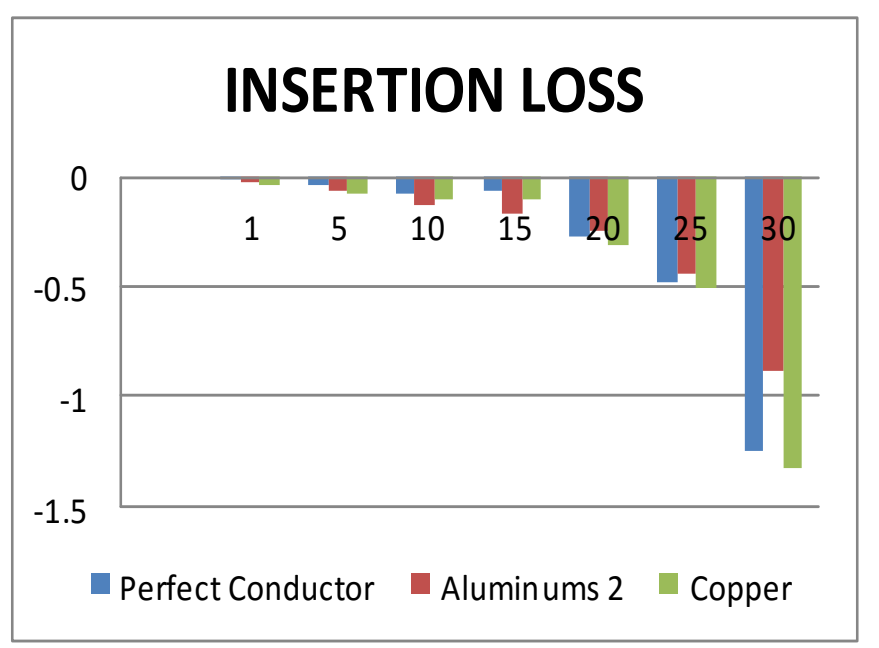

Fig-11: Insertion loss

\section{CONCLUSION}

This paper presents the three designed unlike media transition model using LTCC technique. The designed conductors are of silver and copper for microstrip to stripline. These are compared with the perfect conductor model. The return loss and insertion loss of copper conducting material is ( $-33.2 \mathrm{~dB}$ to $-6.71 \mathrm{~dB} \&-0.0366 \mathrm{~dB}$ to $-1.326 \mathrm{~dB}$ respectively) better than silver conducting material $(-34.59 \mathrm{~dB}$ to $-8.54 \mathrm{~dB}$
[2] Young C L and Chul S P, "A Novel CPW-toStripline Vertical Via Transition Using a Stagger Via Structure and Embedded Air Cavities," IEEE, APMC Proceedings, Koria, 2005.

[3] J. Laskar, A. Sutono, C.-H. Lee, M. Davis, M. Maeng, N. Lal, K. Lim, S.Pinel; M. Tentzeris, A. Obatoyinbo, "Development of tegrated 3D radio front-end system-on-package (SOP)" - $2003 \mathrm{GaAs}$ IC Symp. Dig., pp. 215 -218, Oct. 2001.

[4] C.-H. Lee, A. Sutono, S. Han, K. Lim, S. Pinel, E.M. Tentzeris, J. Laskar: "A compact LTCC-based Kuband transmitter module", IEEE Trans. Components, Packaging \& Manufacturing Technology , vol. 25, pp. 374384, Aug. 2002.

[5] A. Panther, C. Glaser, M. G. Stubbs, J. S. Wight, "Vertical Transition in Low Temperature Co-fired Ceramics for LMDS Applications," IEEE MTT-S Digest, 2001.

[6] A. Gamez-Machado, D. V. Martin, A. A. Lopez, G. Menoyo, "Microstrip-to-Stripline Transition on LTCC," IEEE MTT-S, Spain, 2011.

[7] J. S. Izadian, S. M. Izadian, "Microwave Transition Design,” Artech House, Germany, pp. 01-33, 1988.

[8] R. Valois, D. Baillargeat, S. Verdeyme, M. Lathi, T. Jaakola, "High Performance of Shielded LTCC Vertical Transition From DC up to 50GHz," IEEE Transaction on Microwave Theory and Techniques, France, Vol, 53, Jun-2005.

[9] AWRDE Getting Strated Guide: Chapter 7. MWO: Using the Electromagnetic Simulator, pp 1-31. 